\title{
Bioactivity of ethanol extracts from Eucalyptus bosistoana F. Muell. heartwood
}

\author{
Gayatri Mishra ${ }^{(1)}$, \\ Ashley Garrill ${ }^{(2)}$, \\ Clemens M Altaner ${ }^{(1)}$
}

\begin{abstract}
Introduction
E. bosistoana is a tree growing up to $60 \mathrm{~m}$ in height. It grows naturally in mixed forests on fertile soils and river flats along the south eastern Australian coast from eastern Gippsland to Sydney. Its dense timber is ranked as class 1 durable, lasting more than 25 years in-ground (Bootle 2005). The species has attracted attention in New Zealand because of its good wood properties and ability to tolerate the cooler climatic conditions. Work is underway to establish a durable hardwood industry in New Zealand based on sustainably grown plantation eucalypts, which can supply the demand for preservative free durable timber (Altaner et al. 2017). A prerequisite is to ensure

abundant amounts of quality timber, i.e., naturally durable heartwood. However, no information is available about the chemical composition of $E$. bosistoana heartwood and its relationship to natural durability.

In eucalypts in general, heartwood extractives are predominately comprised of polyphenols such as condensed tannins (e.g., proanthocyanidins, polyflavonoid tannins, catechol), hydrolysable tannins (i.e., the esters of gallic and ellagic acids) or cinnamic acid derivatives (Rudman 1964, Hillis 1971, 1991, Conde et al. 1995). The quantity and composition of these extractives varies between species, between individual trees of a species and also within a tree (Hillis 1987, Taylor et al. 2002). The nat-
\end{abstract}

\begin{abstract}
Variability in bioactivity and chemical composition of Eucalyptus bosistoana $\mathrm{F}$. Muell. heartwood extracts between individual trees from two different sites were investigated. Combining the results of fungal assays and quantitative gas chromatography (GC) of the extracts allowed the investigation of bioactive compounds. The bioactivity of extracts was assessed against white rot (Trametes versicolor [L.] Lloyd) and brown rot (Coniophora cerebella Pers.). Ethanol extracts from $E$. bosistoana heartwood were less effective on the white rot than against the brown rot. Variability in the bioactivity of extracts against the two fungi was observed between the trees. A site effect in the bioactivity was found for the white rot but not the brown rot. Bioactivity of the extracts against the white rot was not correlated to that against the brown rot. The absence of a relationship between of effects of the extracts on the relative growth rates of the white rot and the brown rot indicated that the two fungi were affected by different compounds. Thirty two compounds were quantified in $E$. bosistoana ethanol extracts by GC, of which six (benzoic acid, hexadecanoic acid, 1,5-dihdroxy-12-methoxy-3,3-dimethyl-3,4-dihydro-1H-anthra[2, 3-c]pyran-6,11-dione, octadecanoic acid, polyphenol and beta-sitosterol) were identified. Significant variability in eight compounds was found between the two sites. Multivariate (PLSR) analysis identified compounds at the retention times $\mathbf{1 0 . 2}$ and $\mathbf{1 1 . 5}$ min (hexadecanoic acid) to be most related to the bioactivity of the $E$. bosistoana heartwood extracts against white rot and brown rot.
\end{abstract}

Keywords: Brown Rot, Extractives, Fungal Assays, Gas Chromatography, Heartwood, White Rot

(1) School of Forestry, University of Canterbury, Christchurch 8140 (New Zealand); (2) School of Biological Sciences, University of Canterbury, Christchurch 8140 (New Zealand)

@ Clemens M Altaner (clemens.altaner@canterbury.ac.nz)

Received: Feb 15, 2019 - Accepted: Jul 23, 2019

Citation: Mishra G, Garrill A, Altaner CM (2019). Bioactivity of ethanol extracts from Eucalyptus bosistoana F. Muell. heartwood. iForest 12: 467-473. - doi: 10.3832/ifor3072-012 [online 2019-10-14]

Communicated by: Giacomo Goli ural durability of timber does not necessarily correspond to the amount of extractives (i.e., extractive concentrations), but also depends on the composition of extractives (Taylor et al. 2002). Therefore, heartwood durability research in a breeding programme needs to consider the most potent extracts and their chemical composition for the next generation durability improvement. The variability in extractive content and composition, which exists between trees of a species, is influenced by environmental and genetic factors. Variation in extractive content in E. globulus Labill. heartwood was observed between trees and sites (Stackpole et al. 2011). For example soil type was reported to influence the amount of lipophilic extractives in E. dunnii Maiden and E. grandis W. Hill ex Maiden (Kilulya et al. 2014). Mosedale et al. (1996a) reported variation in the concentration of ellagitannins in the heartwood of oak species (Quercus robur L. and Q. petraea [Matt.] Liebl.) between forests and found that the ellagitannin content was under strong genetic control (Mosedale et al. 1996b). Variation in decay resistance among individual trees of E. cladocalyx $\mathrm{F}$. Muell. has also been reported to be under genetic control (Bush et al. 2011). The authors also highlight the need to study the typically ignored environmental effects on 
natural durability (Bush et al. 2011).

Eucalyptus species can be classified into four groups, based on the colour of the heartwood (Hillis 1991). Condensed tannins are characteristic in the heartwood of a group with pink to red brown heartwood (e.g., E. camaldulensis Dehnh., E. grandis, E.marginata Donn ex Sm.), while hydrolysable tannins are characteristic for a group with pale-light coloured heartwood (e.g., $E$. delegatensis R.T. Baker.). A third group with brown heartwood (e.g., E. wandoo Blakeley) features hydrolysable tannins and stilbenes, which darken in sunlight. And a fourth group with heartwood that has a greasy feel (e.g., Corymbia maculata [Hook.] K.D. Hill \& L.A.S. Johnson and E. microcorys $\mathrm{F}$. Muell.) contains, in addition to ellagic acid and ellagitannins, a significant amount of unsaponifiable substances including steroids.

The quantification of all extractive components is difficult because the numerous compounds have different physical and chemical properties. However, identification and quantification of some compounds is feasible by chromatographic methods such as Gas Chromatography (GC) or High Performance Liquid Chromatography (HPLC) combined with mass spectrometry (MS). GC has been a commonly used technique for the characterisation of wood extractives (Sitholé et al. 1992, Gutiérrez et al. 1998, Fernandez et al. 2001). However, heartwood extractives often need to be derivatized by methylation, silylation or acetylation for GC analysis (Fernandez et al. 2001, Davies et al. 2014).

The objectives of this study were to: (i) quantify the variability in bioactivity of $E$. bosistoana heartwood extracts; (ii) quantify the variability of the composition of $E$. bosistoana heartwood extracts; and (iii) identify key chemical compounds affecting the growth of wood decaying organisms. The bioactivity of $91 \mathrm{E}$. bosistoana extracts from two different sites was investigated. A constant amount of extract was added to agar in a petri dish and then the growth rate of wood decaying fungi on extracts was compared to the growth rate on pure agar. The resulting difference in growth rate between extracts was due to the relative amounts of the individual components in the extract, not the amount of extract. Variation in extractive compounds was quantified by gas chromatography for all 91 trees and subsequently correlated to the relative growth rates.

\section{Materials and methods}

\section{Wood material}

Ninety one heartwood disks were obtained from 7 year-old $E$. bosistoana breeding trials, which were planted in 2009. These trees, representing 66 plus trees from the southern Australian distribution of $E$. bosistoana, were grown at two different sites, Lawson and Craven Road ( $41^{\circ} 26^{\prime}$ $\mathrm{S}, 173^{\circ} 56^{\prime} \mathrm{E}$ and $41^{\circ} 43^{\prime} \mathrm{S}, 173^{\circ} \mathrm{O2} 2^{\prime} \mathrm{E}$ ) in Marl- borough, New Zealand. Heartwood powders were obtained by drilling into the cross section of the disks and subsequently milling the collected drill dust in a Wiley mill to pass a 20 mesh screen.

\section{Extracts}

Heartwood powder was extracted using an Accelerated Solvent Extractor (Dinoex ${ }^{\mathrm{TM}}$ ASE $^{\mathrm{TM}}$ 350, Thermo Scientific, Waltham, MS, USA) equipped with $33 \mathrm{~mL}$ cells. In each run approximately $8 \mathrm{~g}$ milled heartwood was extracted with HPLC grade ethanol. The extraction conditions were two cycles at $70^{\circ} \mathrm{C}$ for $15 \mathrm{~min}$ (static time) followed by rinsing with $100 \%$ of the cell volume, resulting in approximately $70 \mathrm{~mL}$ of extract. The extract solutions were transferred to predried aluminium foil trays of known mass and placed in the fume hood overnight to evaporate the ethanol. The extracts were further dried using a vacuum oven at $60^{\circ} \mathrm{C}$, mimicking commercial hardwood timber drying temperatures, to remove moisture. The mass of each oven-dried extract was measured and the extractive content was calculated on a dry mass basis.

\section{Fungal assays}

The white rot ( $T$. versicolor) and brown rot (C. cerebella) were obtained from the School of Biological Sciences culture collection, University of Canterbury (NZ). T. versicolor and C. cerebella (facultative synonym for C. puteana) are listed in European standards EN-113 (1996), EN-350-1 (1994) and by the Australian Wood Preservation Committee (AWPC 2007) for accessing the durability of wood.

Ten $\mathrm{mL}$ of autoclaved $\left(121^{\circ} \mathrm{C}, 12 \mathrm{~min}\right)$ potato dextrose agar (Oxoid ${ }^{\oplus}$ - containing 4.0 $\mathrm{g} \mathrm{L}^{-1}$ potato extract, $20.0 \mathrm{~g} \mathrm{~L}^{-1}$ dextrose and $15.0 \mathrm{~g} \mathrm{~L}^{-1}$ agar) was poured into $7 \mathrm{~cm}$ petri dishes. $100 \mu \mathrm{L}(250 \mathrm{mg} / \mathrm{mL})$ or $50 \mu \mathrm{l}(93.75$ $\mathrm{mg} \mathrm{mL}^{-1}$ ) of dimethyl sulfoxide (DMSO) extract solution were spread onto the surface of the solidified agar with a disposable spreader for white rot and for brown rot tests, respectively. The dishes were inoculated with a $0.5 \mathrm{~mm}$ diameter fungi transplant and stored at $24{ }^{\circ} \mathrm{C}$. Controls were run with pure agar and $100 \mu \mathrm{L}$ or $50 \mu \mathrm{L}$ DMSO, respectively. Five replicates for each fungi and extract were conducted resulting in 1160 dishes. The assays were conducted in 25 batches over a period of 20 weeks. The radius of the fungus in each plate was measured every $24 \mathrm{~h}$ for up to 6 days. The growth rates $\left(\mathrm{cm} \mathrm{h}^{-1}\right)$ were calculated by fitting a linear regression for the diameter against time for each dish. To account for differences in growing conditions between the batches, the relative growth rate (RGR, \%) was calculated (eqn. 1) using the agar controls only:

$$
R G R(\%)=\frac{D s}{D c} \cdot 100
$$

where $D s$ is the growth rate in the plate containing the tested antifungal agent and $D c$ is the growth rate in the control plate.
There was no evidence of different growth rates in the two type of controls for both, white rot $(t=0.24, p=0.814)$ and brown rot $(t=0.15, p=0.878)$. This confirmed that the used quantities of DMSO had no effect on the test, and the changes in growth rate were caused by the heartwood extracts.

\section{Gas chromatography (GC)}

For each sample, $10 \mathrm{mg}$ of dried heartwood extract were mixed with $90 \mu \mathrm{L}$ pyridine to which $10 \mu \mathrm{L}$ internal standard solution ( $5 \mathrm{mg}$ betulin dissolved in $1 \mathrm{~mL}$ of pyridine - Sigma Aldrich ${ }^{\circledast}$, St. Louis, MO, USA) was added. A $15 \mu \mathrm{L}$ aliquot of this solution was trimethylsilylated at room temperature using $50 \mu \mathrm{L}$ of N,O-bis(trimethylsilyl)trifluoroacetamide (BSTFA, Supelco Analytical $^{\oplus}$, Sigma Aldrich) in a septum-sealed vial for $20 \mathrm{~min}$. The trimethylsilyl derivatives were analysed with a gas chromatograph (Agilent $7820 \mathrm{~A}^{\mathrm{TM}}$, Santa Clara, CA, USA), fitted with a fused-silica capillary column (Agilent DB- $5^{\mathrm{TM}}-30 \mathrm{~m} \times 0.320 \mathrm{~mm} \times 0.25 \mu \mathrm{m}$ ) using helium as the carrier gas and FID detection at $300{ }^{\circ} \mathrm{C}$. The initial oven temperature was set to $116{ }^{\circ} \mathrm{C}$, ramped up to $280^{\circ} \mathrm{C}$ at $7{ }^{\circ} \mathrm{C} \mathrm{min}-1$ and held for $20 \mathrm{~min}$. Each sample was analysed twice after a blank and a pyridine run.

Individual compounds were identified by comparing the E. bosistoana heartwood extracts with an E. globoidea Blakely heartwood extract, in which some compounds were previously identified by GS-MS (Schroettke 2018).

\section{Data extraction from chromatograms and data analysis}

The largest 33 peaks of the chromatograms were integrated using the integration tool in the ChemStation ${ }^{\mathrm{TM}}$ software (Agilent, Rev.c.01.07) and refined manually. The peak areas were normalised by the internal standard before duplicate runs were averaged.

Data analysis was performed using $\mathrm{R}$ programming language ( $R$ Core Team 2013). Multivariate analysis (Partial Least Squares Regression) between the quantified heartwood compounds and the relative growth rates of white rot (T. versicolor) and brown rot (C. cerebella) was performed using the package plsdepot version 0.1.17 (Sanchez 2012). Tukey tests was performed to analyse significance of differences between the bioactivity of heartwood extracts. Differences in the chemical composition between sites were analysed for each of the quantified compound with a t-test after normalisation by the internal standard.

\section{Results and discussion}

The summary statistics for extractive content and relative growth rates of white rot ( $T$. versicolor) and brown rot (C. cerebella) in heartwood extracts of 91 samples are shown in Tab. 1. The extract content was variable within the two sites. Brown rot was more susceptible to the $E$. bosistoana 
heartwood extracts than the white rot, as the growth was slowed more by smaller amounts of extract. The effect was also more variable.

\section{Bioactivity of extracts}

The relative growth rate of white rot $(t=$ 42.65, $\left.p<2.2 \cdot 10^{-16}\right)$ and brown $\operatorname{rot}(t=27.13$, $\mathrm{p}<2.2 \cdot 10^{-16}$ ) were significantly lower when the cultures were exposed to the ethanol extracts of $E$. bosistoana heartwood compared to the controls. No relationship between the effect of a tree extract on the relative growth rates of the white rot and the brown rot was observed $(t=0.09, p=$ 0.932 - Fig. 1). Similar observations were reported by Davies et al. (2014) for Sequoia sempervirens (D. Don) Endl. (redwood) and Ohtani et al. (2009) for Cryptomeria japonica (L.f.) D. Don (sugi) heartwood extracts. This suggested that the fungi were inhibited by different compounds in the extracts. Kirker et al. (2013) reported that individual components in extracts confer durability rather than bulk presence of the extractive. For example in vitro tests showed that thujaplicin, a natural fungicide in the heartwood extracts of Thuja plicata Donn ex D. Don (western red cedar), was found to be toxic to brown rot, but not so effective against white rot (Roff \& Atkinson 1954). Similarly, naphthoquinone, a compound in the heartwood of Tectona grandis L.f. (teak) was found to have a more negative effect on the brown rots Polyporus palustris (Berk. \& M.A Curtis) and Gloeophyllum trabeum (Pers.) Murrill. than the white rots T. hirsuta (Wulfen) Lloyd, T. versicolor and Pycnoporous sanguineus (L.) Murrill. (Thulasidas \& Bhat 2007). Therefore, as stated by Taylor et al. (2002) and Morris \& Stirling (2012), it is not possible to focus on a single heartwood compound to understand the resistance of the wood against multiple biodegrading organisms.

No correlation was observed between the extractive content in the wood, which was variable, and the relative growth rates of the white rot $\left(R^{2}=0.010\right)$ and brown rot $\left(R^{2}=0.004\right)$ exposed to a fixed quantity of extract. However, when taking the site factor into account the extractive content had a negative influence on the bioactivity towards the white rot for the Lawson, but not the Craven Road site (Tab. 2). This suggested that the trees with elevated extractive contents at the Lawson site deposit more compounds into the heartwood, which were not bioactive against $T$. versicolor. For the brown rot C. cerebella no evidence of a relationship between growth rate and extractive content in the wood was found in either of the two sites (Tab. 2). This suggested that extract content was not associated with a change in extractive composition, increasing or decreasing the amount of fungicidal compounds for these fungi.

\section{Variation in bioactivity}

Variation in the relative growth rates of

Tab. 1 - Summary statistics of extractive content in E. bosistoana heartwood from 7 year-old trees and the effect of ethanol extracts on the relative growth rates of the white rot Trametes versicolor and the brown rot Coniophora cerebella for 2 sites. $(R G R)$ : relative growth rate; (CV): coefficient of variation; $(n)$ : number of samples.

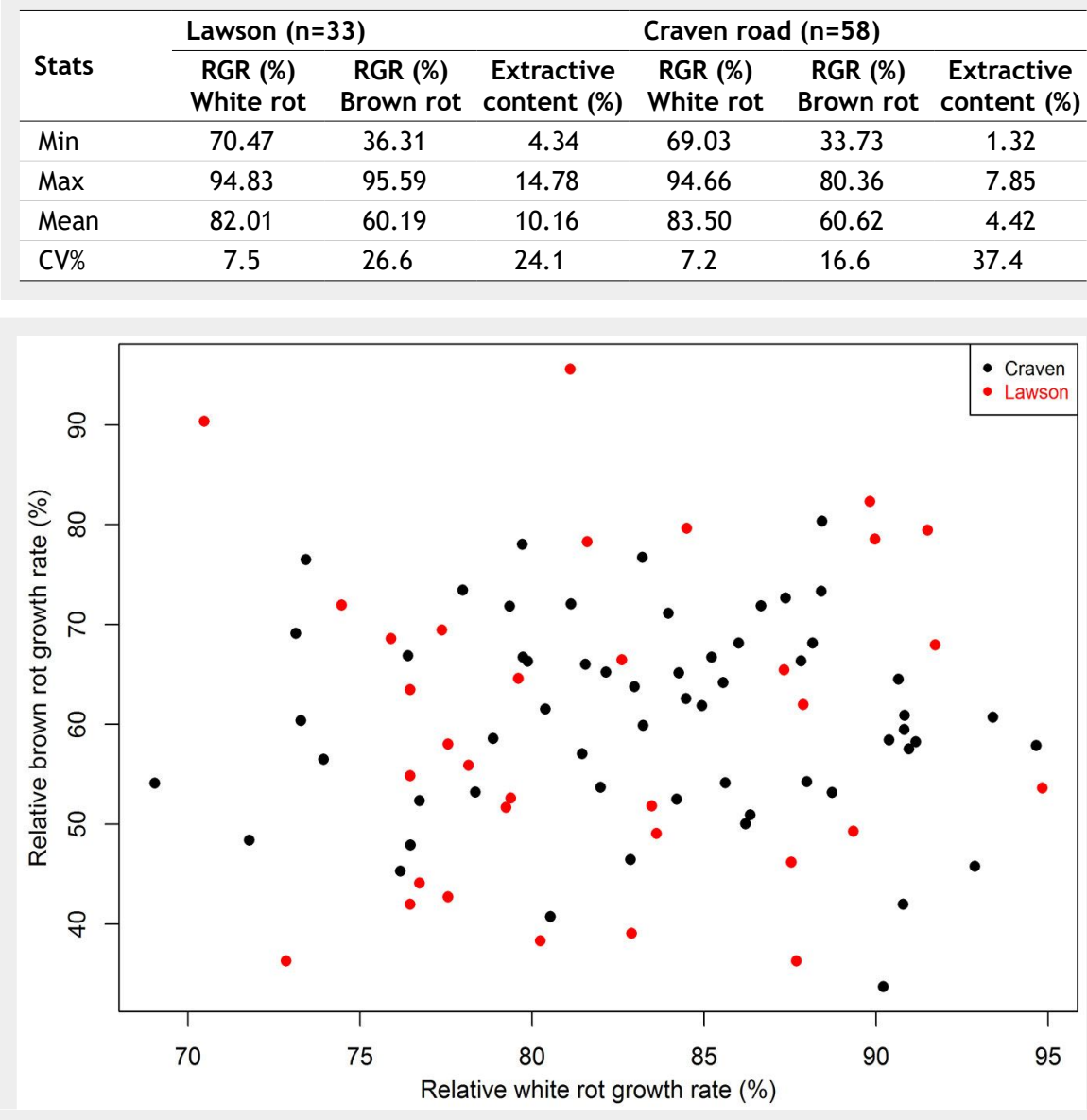

Fig. 1 - Relationship between the relative growth rates of white rot ( $T$. versicolor) and brown rot (C. cerebella) when exposed to ethanol extracts of $E$. bosistoana heartwood $\left(R^{2}=0.01\right)$.

white rot and brown rot when exposed to E. bosistoana heartwood extract was observed between trees (Fig. 2). Statistical analysis showed significant differences between the trees, suggesting an influence of genetic factors on the composition of heartwood extracts of $E$. bosistoana. Similarly, variation within and between trees and populations was observed in the concentration of heartwood tannins in oaks (Puech \& Mosedale 1999). However, the relative importance of different factors such as species, forest origin (or provenance) that influenced the variation in the concentration of ellagitannins remained

Tab. 2 - Relationship between relative growth rates of white rot ( $T$. versicolor) and brown rot (C. cerebella) when exposed to a fixed amount of ethanol extract of E. bosistoana heartwood with the extractive content in the wood for two sites, Lawson and Craven Road.

\begin{tabular}{lcccccc}
\hline \multirow{2}{*}{ Sites } & White rot & \multicolumn{5}{c}{ Brown rot } \\
\cline { 2 - 7 } & Slope & $t$-test & P-value & Slope & $t$-test & P-value \\
\hline Lawson & 1.01 & 2.45 & 0.020 & -0.42 & -0.35 & 0.723 \\
Craven road & 0.77 & 1.54 & 0.128 & -0.87 & -1.04 & 0.303 \\
\hline
\end{tabular}




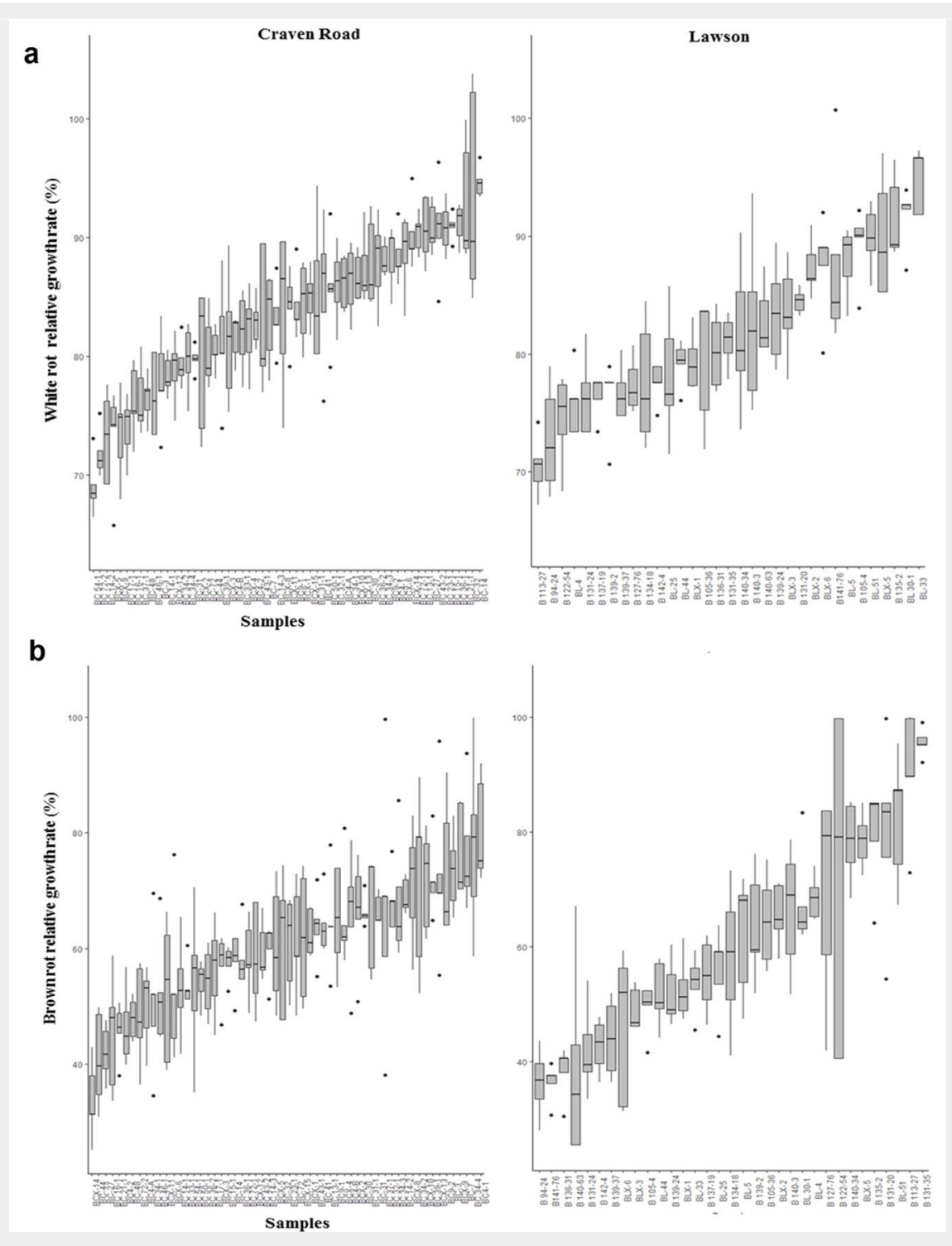

Fig. 2 - Box-and-whisker plots representing variation in relative growth rates of (a) white rot ( $T$. versicolor) and (b) brown rot (C. cerebella) when exposed to ethanol extracts of the heartwood of 7-year old E. bosistoana for individual trees and sites.

tive growth rates was observed between the two sites for the brown rot (Tab. 3). Although statistically significant $(p=0.028)$, the difference in the relative growth rates between both sites for the white rot was small, with $82.01 \%$ and $83.50 \%$ for Lawson and Craven Road, respectively (Tab. 3). Reports on differences in durability between sites were typically associated with a higher extractive content in wood, for which was normalised in this experiment. For example, Harju et al. (2003) found that

Pinus sylvestris L. from a site with more durable wood also contained higher amounts of heartwood extractives (total acetonesoluble extractives, resin acids, pinosylvin and the total phenolics quantified as tannin acid equivalents). This was in line with observations on teak, for which variability in natural durability, total extractive content as well as the amounts of individual compounds was reported between trees, plantations and geographical zones (Windeisen et al. 2003, Kokutse et al. 2006, Thulasidas

Tab. 3 - Site effect on the relative growth rates of white rot (T. versicolor) and brown rot (C. cerebella) exposed to E. bosistoana heartwood extract.

\begin{tabular}{lcccc}
\hline \multirow{2}{*}{ Fungi } & \multirow{t}{*}{-test } & P-value & \multicolumn{2}{c}{$\begin{array}{c}\text { Mean in group } \\
\text { (sample estimate, \%) }\end{array}$} \\
\cline { 4 - 5 } & & & Lawson & Craven road \\
\hline White rot & 2.21 & 0.028 & 82.01 & 83.50 \\
Brown rot & 0.27 & 0.791 & 60.19 & 60.62 \\
\hline
\end{tabular}

\& Bhat 2007). Morais \& Pereira (2012) reported an influence of site on the extractive content in E. globulus.

\section{Compounds in ethanol-soluble extracts} of $E$. bosistoana heartwood

The chemical composition in the ethanol extracts was analysed by GC. Six compounds were identified (benzoic acid, hexadecanoic acid, 1,5-dihdroxy-12-methoxy-3, 3-dimethyl-3,4-dihydro-1H-anthra[2,3-c]pyran-6,11-dione, octadecanoic acid, polyphenol and beta-sitosterol) by comparing them with E. globoidea extracts, which were previously analysed by GC-MS (Schroettke 2018). The unspecified "polyphenol" peak at 25.1 min might be catechin, which was observed in heartwood of $E$. camaldulensis (Benouadah et al. 2018).

Similarities in the chemical composition of heartwood extracts of eucalyptus species have been described (Hillis 1991). While compounds such as stilbenes have been suggested as taxonomic marker for closely related eucalyptus species, the heartwood compound, 3',4-tri-o-methylellagic acid-4'-glucoside was considered a marker for the close relationship between the eucalyptus groups iron barks (e.g., E. paniculata Sm. and E. sideroxylon A. Cunn. ex Woolls) and boxes, to which E. bosistoana belongs (Brooker 2000, Hillis et al. 1974).

Fig. 3 shows the variation in relative proportions of $32 \mathrm{E}$. bosistoana compounds between two sites. Statistical analysis suggested significant variation for eight compounds between the sites (Fig. 3 in boxes). Investigation of the influence of geographical origin and species on extractives in oaks (Q. alba, Q. robur and Q. petraea) suggested variations in the content of whiskey lactone and ellagitannins differentiated species, whereas the content of eugenol, 2phenylethanol, vanillin, and syring aldehyde were the most important features for distinguishing the geographical origin within species (Prida \& Puech 2006). Similar observations were reported for the content of volatile compounds (cis- and trans-methyl- $\gamma$-octalactones, furfural, 5-methylfurfural, guaiacol, eugenol and vanillin) in Q. robur and Q. petraea (Guchu et al. 2006).

\section{Identification of bioactive compounds}

The normalised peak areas of 32 quantified heartwood compounds were correlated with the relative growth rates of the brown rot and the white rot fungi. Multivariate analysis identified two groups of compounds (Fig. 4). Compounds with retention times of 10.2 and 11.5 (hexadecanoic acid) min were most important for predicting the bioactivity of the $E$. bosistoana heartwood extracts towards white rot (T. versicolor) and brown rot (C. cerebella). The other 30 compounds were grouped together and differed in the second principal component for the white rot and in the first principal component for the brown rot. 
Fig. 3 - Box-and-whisker plots representing the amount of individual heartwood compounds in $\mathrm{E}$. bosistoana for two sites

(Lawson and Craven Road). Eight compounds showing significant differences between the sites are highlighted by a red box. (RT): retention time in min; ( $y$-axis units): peak area in relation to internal standard.
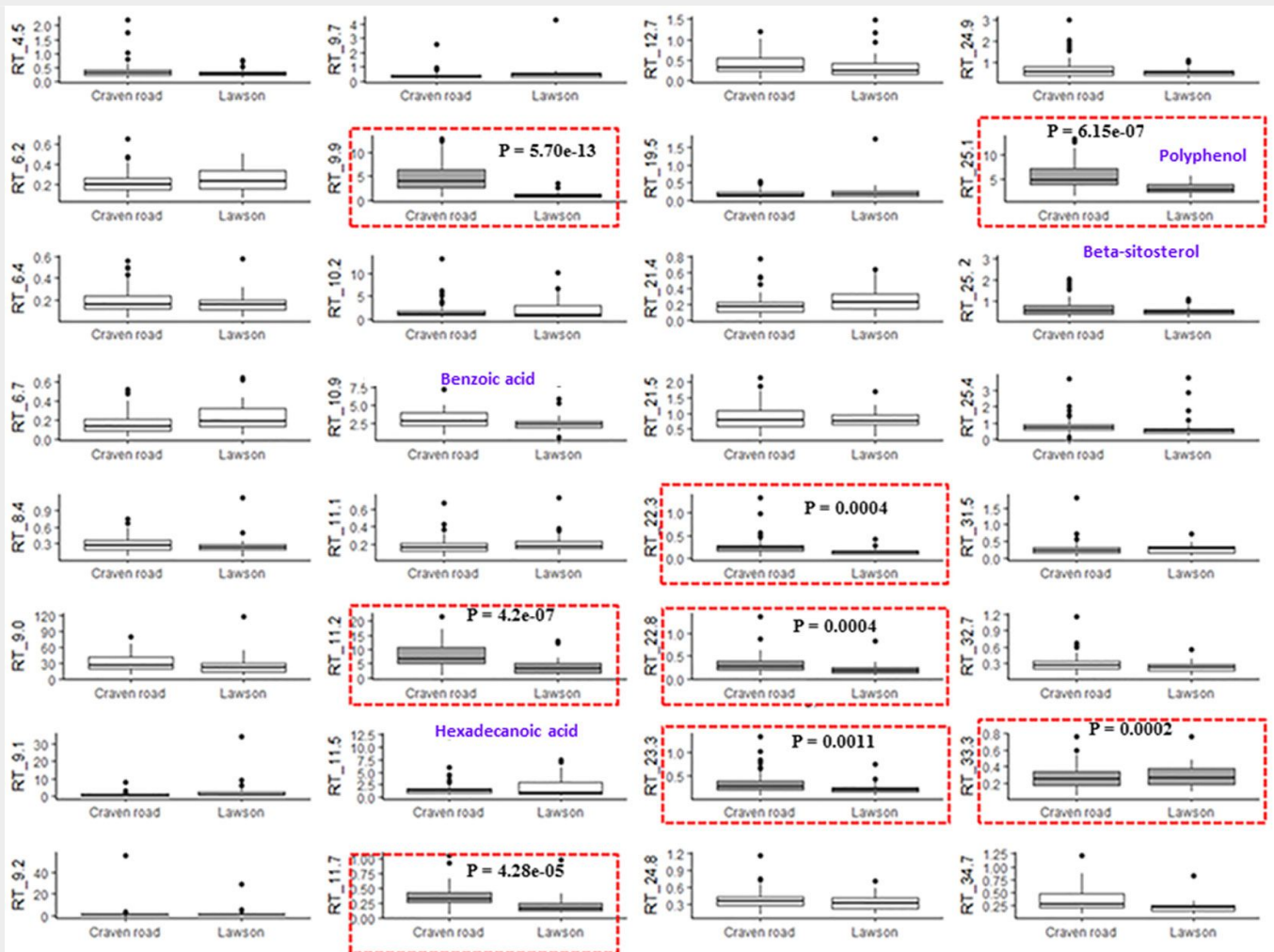

No clear explanatory factor was found to explain the variation in bioactivity by the two principal components. However, for both fungi, a small part of the variation in bioactivity was explained by the two principal components. The total variance in relative growth rate explained by the first two principal components was $13.2 \%$ (9.2\% and $3.9 \%$, respectively) for the white rot ( $T$. versicolor) and $15.8 \%$ (8.9\% and $6.9 \%$, respectively) for the brown rot (C. cerebella). This suggested that other compounds, not captured in the GC analysis were likely to have contributed to the bioactivity against the fungi. GC relies on compounds entering the gas phase, which is difficult for larger and more hydrophilic molecules. Derivatisation, like acetylation or silylation, can aid the transition of hydrophilic compounds into the gas phase. As this is not necessarily successful, GC analysis of the hydrophilic ethanol extracts form $E$. bosistoana heartwood was likely not to capture larger compounds. HPLC is an alternative method to quantify larger molecular mass compounds in wood extracts (Smeds et al. 2018).

According to its colour, E. bosistoana should (Bootle 2005) fall either into the group of eucalypts which is dominated by condensed (group 1) or hydrolysable (group 2) tannins (Hillis 1991). Ellagitannins in the heartwood extractives from Q. alba L. (white oak) were reported to be less inhibitory to T. versicolor (white rot) than Poria monticola Murrill (brown rot) (Hart \& Hillis 1972), indicating that hydrolysable tannins were lost in the experimental procedure of this work.

\section{Conclusion}

White rot (T. versicolor) was less affected by ethanol-soluble extracts from $E$. bosistoana heartwood than the brown rot (C. cerebella). No relationship was found between the effect of the heartwood extracts of a tree on the growth of the white rot and brown rot, indicating that different compounds in the extracts inhibited the growth of the two fungi. The extractive content in the wood had no effect on the bioactivity of the extracts against the brown rot while a negative influence on the bioactivity towards the white rot was found for one site (Lawson). This sug-
Fig. 4 - Influence of heartwood compounds in $E$. bosistoana heartwood on the growth of the (a) white $\operatorname{rot}(T$. versicolor) and (b) brown rot (C. cerebella) analysed by partial least squares regression analysis (PLSR). Compounds that are near each other are highly correlated in the first two principal components. Compounds at 10.2 and 11.5 (hexadecanoic acid) min aligned with the relative growth rate (orange line) and were considered different to the other 30 compounds grouped together.
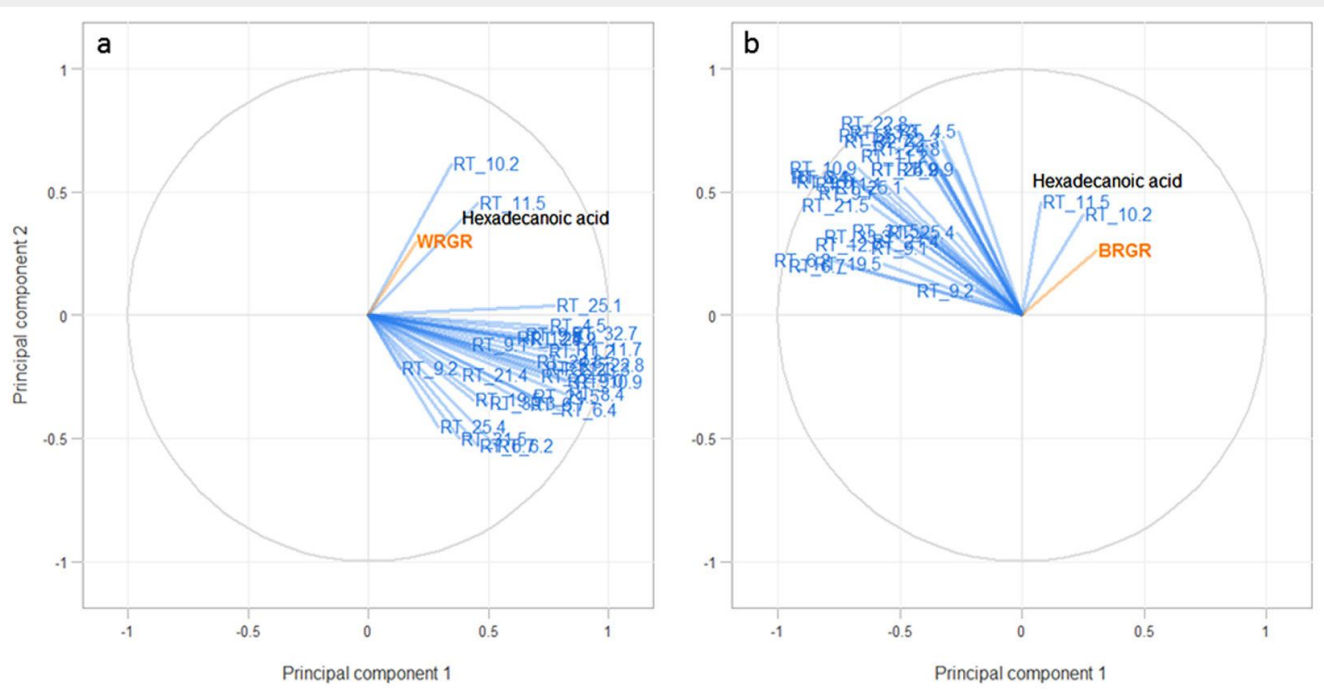
gested that the trees with elevated extractive content at the Lawson site deposited more compounds into the heartwood, which were not bioactive against white rot. Significant variability was found in the bioactivity of $E$. bosistoana heartwood extracts against white rot and brown rot between the trees. The difference in the relative growth rates of white rot between the sites was small and only significant for white rot. Therefore, the site influence on the bioactivity of the heartwood extracts was small.

Thirty-two compounds were quantified by GC in E. bosistoana ethanol extracts of which six were identified. Multivariate (PLSR) analysis identified compounds eluting at 10.2 and 11.5 (hexadecanoic acid) min to be most related to the bioactivity of the $E$. bosistoana heartwood extracts against the tested white rot and brown rot. Significant variation in the quantity of eight compounds was found between the two sites.

\section{List of abbreviations}

- GC: Gas chromatography;

- HPLC: High Performance Liquid Chromatography;

- MS: Mass spectrometry;

- DMSO: Dimethyl sulfoxide.

\section{Acknowledgements}

The authors thank Meike Holzenkämpfer (NZ School of Forestry, University of Canterbury) for assistance with the chemical analysis of the wood extracts. The research was supported by New Zealand Dry land Forests Initiative (NZDFI) and financed through the Ministry of Business, Innovation and Employment (New Zealand) funded "Speciality Wood Products Partnership" (FFRX1501).

\section{References}

Altaner C, Murray T, Morgenroth J (2017). Durable eucalypts on drylands: protecting and enhancing value. Proceeding of the Workshop "Durable eucalypts on drylands: protecting and enhancing value". Blenheim (NZ), 19 Apr 2017. New Zealand School of Forestry, University of Canterbury, Christchurch, New Zealand, pp. 1139.

AWPC (2007). Protocols for assessment of wood preservatives. The Australian Wood Preservation Committee, Clayton, Australia, pp. 30.

Benouadah N, Pranovich A, Aliouche D, Hemming J, Smeds A, Willför S (2018). Analysis of extractives from Pinus halepensis and Eucalyptus camaldulensis as predominant trees in Algeria. Holzforschung 72: 97-104. - doi: 10.1515/hf-20 17-0098

Brooker MH (2000). A new classification of the genus Eucalyptus L'Her. (Myrtaceae). Australian Systematic Botany 13: 79-148. - doi: 10.1071/ SB98008

Bootle KR (2005). Wood in Australia. Types, properties, and uses ( $\left.2^{\text {nd }} e d n\right)$. McGraw-Hill, Australia, pp. 452.

Bush D, McCarthy K, Meder R (2011). Genetic variation of natural durability traits in Eucalyptus cladocalyx (sugar gum). Annals of Forest
Science 68:1057-1066. - doi: 10.1007/s13595-0110121-z

Conde E, Cadahía E, García-Vallejo MC, Fernandez de Simón MB (1995). Polyphenolic composition of wood extracts from Eucalyptus camaldulensis, E. globulus and E. rudis. Holzforschung 49 (5): 411-417. - doi: 10.1515/hfsg.1995.49.5.411

Davies NT, Wu HF, Altaner CM (2014). The chemistry and bioactivity of various heartwood extracts from redwood (Sequoia sempervirens) against two species of fungi. New Zealand Journal of Forestry Science 44: 17-21. - doi: 10.11 86/540490-014-0017-4

Fernandez M, Watson P, Breuil C (2001). Gas chromatography-mass spectrometry method for the simultaneous determination of wood extractive compounds in quaking aspen. Journal of Chromatography A 922: 225-233. - doi: 10.1016/S0021-9673(01)00948-7

Guchu E, Conseulo M, Marato IJD, Lamireo PV, Coello MSP (2006). Influence of the species and geographical location on volatile composition of spanish oak wood (Quercus petraea Liebl. and Quercus robur L.). Journal of Agricultural and Food Chemistry 54: 3062-3066. - doi: 10.1021/jfo53055z

Gutiérrez A, Rio JC, González FJ, Martin F (1998). Analysis of lipophilic extractives from wood and pitch deposits by solid-phase extraction and gas chromatography. Journal of Chromatography A 823: 449-455. - doi: 10.1016/So021-96 73(98)00356-2

Harju AM, Venäläinen $M$, Anttonen S, Viitanen $\mathrm{H}$, Kainulainen P, Saranpää P, Vapaavuori E (2003). Chemical factors affecting the brown-rot decay resistance of Scots pine heartwood. Trees 17 (3): 263-268. [online] URL: http://link.springer. com/article/10.1007/s00468-002-0233-z

Hart JH, Hillis W (1972). Inhibition of wood-rotting fungi by ellagitannins in the heartwood of Quercus alba. Phytopathology 62: 620-626. doi: 10.1094/Phyto-62-620

Hillis W (1971). Distribution, properties and formation of some wood extractives. Wood Science and Technology 5: 272-289. - doi: 10.1007/B Fo0365060

Hillis W, Hart JH, Yazaki Y (1974). Polyphenols of Eucalyptus sideroxylon wood. Phytochemistry 13: 1591-1595. - doi: 10.1016/0031-9422(74)803341

Hillis W (1987). Heartwood and tree exudates. Springer, New York, pp. 268.

Hillis W (1991). Eucalypts: chemistry, uses. Appita Journal 44: 239-244.

Kilulya KF, Msagati TA, Mamba BB, Ngila JC, Bush T (2014). Effect of site, species and tree size on the quantitative variation of lipophilic extractives in Eucalyptus woods used for pulping in South Africa. Industrial Crops and Products 56: 166-174. - doi: 10.1016/j.indcrop.2014.0 2.017

Kirker G, Blodgett A, Arango R, Lebow P, Clausen $C$ (2013). The role of extractives in naturally durable wood species. International Biodeterioration and Biodegradation 82: 53-58. - doi: 10.1016/j.ibiod.2013.03.007

Kokutse AD, Stokes A, Baillères $H$, Kokou K, Baudasse C (2006). Decay resistance of Togolese teak (Tectona grandis Lf) heartwood and relationship with colour. Trees 20: 219-223. - doi: 10.1007/s00468-005-0028-0
Morais MC, Pereira H (2012). Variation of extractives content in heartwood and sapwood of Eucalyptus globulus trees. Wood Science and Technology 46: 709-719. - doi: 10.1007/s00226011-0438-7

Morris PI, Stirling R (2012). Western red cedar extractives associated with durability in ground contact. Wood Science and Technology 46: 9911002. - doi: 10.1007/s00226-011-0459-2

Mosedale J, Charrier B, Crouch N, Janin G, Savill $P$ (1996a). Variation in the composition and content of ellagitannins in the heartwood of European oaks (Quercus robur and Q. petraea). A comparison of two French forests and variation with heartwood age. Annals of Forest Science 53 (5): 1005-1018. - doi: 10.1051/forest:199 60508

Mosedale J, Charrier B, Janin G (1996b). Genetic control of wood colour, density and heartwood ellagitannin concentration in European oaks (Quercus petraea and Q. robur). Forestry 69: 111124. - doi: 10.1093/forestry/69.2.111

Ohtani Y, Noguchi T, Ichiura H (2009). Relationship between sugi (Cryptomeria japonica) buttrot disease and norlignans in the heartwood. Journal of the Japan Wood Research Society 55: 92-100. - doi: 10.2488/jwrs.55.92

Prida A, Puech JL (2006). Influence of geographical origin and botanical species on the content of extractives in American, French, and East European oak woods. Journal of Agricultural and Food Chemistry 54: 8115-8126. - doi: 10.1021/jfo6 16098

Puech FF, Mosedale JR (1999). The tannins of oak heartwood: structure, properties, and their influence on wine flavor. American Journal of Enology and Viticulture 50: 469-478. [online] URL: http://www.ajevonline.org/content/50/4/4 69.short

Roff J, Atkinson J (1954). Toxicity tests of a water-soluble phenolic fraction (thujaplicin-free) of western red cedar. Canadian Journal of Botany 32: 308-309. - doi: 10.1139/b54-025

Rudman P (1964). Durability in the genus Eucalyptus. Australian Forestry 28: 242-257. - doi: 10.1080/00049158.1964.10675949

Sanchez G (2012). Partial least squares (PLS) data analysis methods. $\mathrm{R}$ package version 0.1.17, web site. [online] URL: https://cran.rproject.org/web/packages/plsdepot/plsdepot.p df

Schroettke N (2018). Natural variability in the extract composition of Eucalyptus globoidea. Master's thesis, MSc in Forestry, Institute of Chemical Wood Technology. University of Hamburg, Germany, pp. 57.

Sitholé B, Sullivan J, Allen L (1992). Identification and quantitation of acetone extractives of wood and bark by ion exchange and capillary GC with a spreadsheet program. Holzforschung 46: 409-416. - doi: 10.1515/hfsg.1992.46.5.409 Smeds AI, Eklund PC, Willför SM (2018). Characterization of high-molar-mass fractions in a Scots pine (Pinus sylvestris L.) knotwood ethanol extract. Holzforschung 72: 201-213. - doi: 10.1515/hf-2017-0079

Stackpole D, Vaillancourt R, Alves A, Rodrigues J, Potts $B$ (2011). Genetic variation in the chemical components of Eucalyptus globulus wood. G3: Genes, Genomes, Genetics 1: 151-159. - doi: 10.15 $34 / g 3.111 .000372$ 
Taylor AM, Gartner BL, Morrell JJ (2002). Heartwood formation and natural durability - A review. Wood and Fiber Science 34: 587-611. [online] URL: http://ir.library.oregonstate.edu/con cern/articles/rj430494s

R Core Team (2013). R: a language and environment for statistical computing. R Foundation for Statistical Computing, Vienna, Austria. [on- line] URL: http://www.r-project.org

Thulasidas P, Bhat K (2007). Chemical extractive compounds determining the brown-rot decay resistance of teak wood. Holz als Roh- und Werkstoff 65: 121-124. - doi: 10.1007/s00107-0060127-7

Wilkes J (1984). The influence of rate of growth on the density and heartwood extractive con- tent of Eucalypt species. Wood Science and Technology 18: 113-120. - doi: 10.1021/eso0120a 013

Windeisen E, Klassen A, Wegener G (2003). On the chemical characterisation of plantation teak wood from Panama. Holz als Roh- und Werkstoff 61: 416-418. - doi: 10.1007/s00107-0030425-2 